Article

\title{
Sensitization to Fragrance mix-1 in Patients with Contact Dermatitis in Nord-East of Italy: 1996-2016 Time Trend and Gender Effect
}

\author{
Francesca Larese Filon*(D) and Marcella Mauro \\ Clinical Unit of Occupational Medicine, 32124 Trieste, Italy; marcella.mauro82@gmail.com \\ * Correspondence: larese@units.it; Tel.: +39-335-526-5204
}

Received: 13 February 2019; Accepted: 15 March 2019; Published: 27 March 2019

\begin{abstract}
Background: Fragrance sensitization is common in Italy and their constituents are used in many cosmetics and detergents. The objective of the study was to analyze the temporal trend of sensitivity to fragrance mix-1 in northeastern Italy and to evaluate gender differences; (2) Methods: From 1996 to 2016, 27,381 consecutive patients with suspected allergic contact dermatitis were patch tested. Individual characteristics were collected through a standardized questionnaire in six departments of dermatology or occupational medicine; (3) Results: The overall prevalence of sensitization to fragrance mix- 1 was $7.3 \%$; the prevalence was significantly higher in women $(7.7 \%)$ than in men (6.3\%). From 1996 to 2016, we observed an increase of this sensitization, ranging from $6.2 \%$ to $7.7 \%$ in males and from $7.2 \%$ to $9.1 \%$ in females; (4) Conclusions: Our study showed that contact allergy to fragrance mix-1 is important in both sexes and prevalence is increasing over time, despite the introduction of new fragrances with lower sensitization potential. There is the need to reduce the use of fragrances mix-1 to stop the increase of sensitization in exposed subjects.
\end{abstract}

Keywords: fragrance mix-1; patch test; epidemiology; allergic contact dermatitis; gender

\section{Introduction}

After metals, sensitization to fragrance mix-1 is high in Europe ranging between 6 to $14 \%$ in patients with contact dermatitis, with wide variability between countries [1-4]. Austria presented the highest prevalence in Europe (13.63\%; 95\% CI 11.57-15.1) in the period 2009-2012 [1] and Spain, the lowest (4.7\% in Silvestre et al. [2] in 2018), while in Brazil, Hafter et al. in 2018 [5] reported a prevalence of $9.8 \%$. Sensitization to fragrance mix-1 is highly dependent on the age of patients tested, and percentages can be completely different in relation to the presence of pediatric population. Moreover, fragrance mix-1 sensitization is present in the general population [6] with a prevalence of $2.1 \%$ in male and $3.1 \%$ in females.

Sensitization to fragrance mix-1 has shown a fluctuating trend over the years with a peak in 1999, a decrease until 2007 [7,8], and an increase in more recent years [9]. Cosmetics and detergents are the principal causes of sensitization, but topical medications, oils, aromatherapy, and occupational materials can play a role [4,10-12]. Since 2003, European regulations have required the labeling of the 26 known fragrance contact haptens for cosmetics [13] and household detergents if present at a concentration $>10 \mathrm{ppm}$ in leave-on products or $>100 \mathrm{ppm}$ in a rinse-off product [13]. According to Article 19 Regulation No. 1223/2009 (Cosmetics Regulation), cosmetic products should list their ingredients on the packaging. In response to the Commission services' request for an update, the Scientific Committee on Consumer Safety gave an opinion on fragrance allergens in cosmetic products (SCCS/1459/11) on 26-27 June 2012 [14]. In it, the SCCS stated that consumers should be informed about additional fragrance ingredients in cosmetic products, on top of those 26 already 
subject to individual labeling. In the public consultation of 2014, the Commission proposed to amend annex III to the Cosmetics Regulation by obligating additional contact allergens to be labeled individually. On 5 December 2018, an inception impact assessment on fragrance allergens labeling was published [15].

In recent years, cosmetics without fragrance mix-I are available, and their diffusion would contribute to a decrease of sensitization over time, however fragrance sensitization is still a problem in Europe and Italy. Results from studies in different countries have highlighted the heterogeneous prevalence of sensitization to fragrance mix-1 across the population. There are not, in our best knowledge, data on fragrance mix-1 sensitization in the large database in Italy, and therefore the aim of our study was:

1. To verify the time trend of sensitization to fragrance mix 1 from 1996 to 2016 in northeastern (NE) Italy.

2. To study the role of gender in this sensitization.

\section{Materials and Methods}

We analyzed the data of patients with suspected allergic contact dermatitis from 1996 to 2016 (n. 27,381) that were patch tested in five departments of dermatology or occupational medicine in NE Italy-Trieste, Padua, Pordenone, Rovigo, and Trento-Bolzano. All patients completed a standardized questionnaire [16]. The questionnaire collected information about individual characteristics, occupational history, and history of personal and familial atopy. Specific body sites (such as fingers, palms, and dorsa of hands) were aggregated into larger categories (for example "hands"). Sex and age differences were taken into account in order to deeply study fragrance mix-1 sensitization. Our findings were compared with literature data.

\subsection{Patch Test}

Finn Chambers ${ }^{\circledR}$ on Scanpor ${ }^{\circledR}$ tape (Epitest Ltd., Tuusula, Finland) and a selection of haptens from FIRMA (Firenze, Italy) were used to perform patch tests on patients with the European baseline series [16,17]. Fragrance mix-1 consists of eight components: Evernia prunastri (1\%), isoeugenol $(1 \%)$, eugenol $(1 \%)$, cinnamal $(1 \%)$, hydroxycitronellal $(1 \%)$, geraniol $(1 \%)$, cinnamyl alcohol $(1 \%)$, and $\alpha$-amylcinnamal (1\%). Patches were applied on the upper back, and removed after $48 \mathrm{~h}$ (D2). The sites were examined on removal and after 72 (D3) or $96 \mathrm{~h}$ (D4) according to International Contact Dermatitis Research Group guidelines [18]. Reactions of grades,+++ , and +++ in the second examination were considered to be positive. Doubtful reactions ( \pm and '?') were considered to be negative.

\subsection{Statistical Analysis}

Data analysis was performed with the software STATA ${ }^{\mathrm{TM}}$ v. 12.0 (Stata Corp., LP, College Station, TX, USA). Categorical data were cross-tabulated into contingency tables, and compared by use of the chi-square test. The patch test results (sensitization to fragrance mix-1) were analyzed by multivariate logistic regression analysis, considering age as an independent variable (as a continuous variable). Gender analysis was performed to verify a possible increased risk. Odds ratios (ORs) and 95\% confidence intervals (CIs) were estimated from the coefficients and the standard errors of logistic regression output. A fragrance-mix 1 sensitization trend test across ordered groups was performed with Cuzick's test for trend. Patients with missing data for relevant variables were excluded from analysis. A $p$-value of $<0.05$ was established as the limit of statistical significance.

\section{Results}

Figure 1 reports the percentages of sensitization to the top-five sensitizers in our group-fragrance mix-1 sensitization was found in $6.3 \%$ and $7.7 \%$ of men and women $(p<0.05)$, respectively, and this hapten was fourth after nickel, cobalt, and chromium sensitization. 


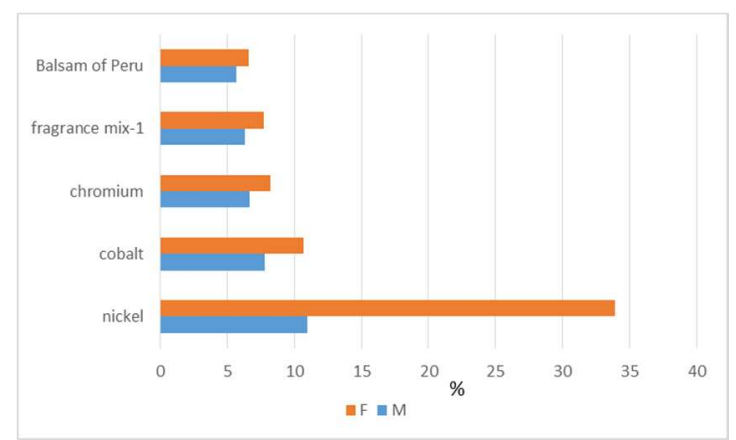

Figure 1. Percentages of sensitization to the top-five sensitizers in both genders.

The general characteristics for subjects sensitized and non-sensitized to fragrance mix-1 are shown in Table 1.

Table 1. Characteristics of the population tested $(n=27,381)$.

\begin{tabular}{cccc}
\hline Characteristics & Sensitized to Fragrance mix-I & Non Sensitized to Fragrance mix-1 & Total (100\%) \\
\hline n. & $1992(7.3)$ & $25,389(92.7)$ & 27,381 \\
Female sex n. (\%) & $1436(72.1)^{*}$ & $17,095(67.3)$ & 18,531 \\
Age (years \pm SD) & $47.1 \pm 17.7^{*}$ & $43.7 \pm 17.4$ & $43.0 \pm 17.5$ \\
Occupational dermatitis (\%) & $268(13.4)$ & $3729(14.7)$ & $3997(14.6)$ \\
Atopic eczema (\%) & $138(8.6)^{*}$ & $1401(6.9)$ & $1539(7.1)$ \\
Hand localization (\%) & $631(31.7)$ & $7881(31.0)$ & $8512(31.1)$ \\
Leg localization (\%) & $123(6.2)$ & $1627(6.4)$ & $1750(6.4)$ \\
Face localization (\%) & $407(20.4)^{*}$ & $4009(15.8)$ & $4416(16.1)$ \\
Age $\geq 40(\%)$ & $1273(63.9)^{*}$ & $13,198(52)$ & 52.9 \\
\hline
\end{tabular}

SD, standard deviation. ${ }^{*} p<0.05$.

Women were found to be more sensitized to fragrance mix-1 than men $(p<0.05)$. The mean age of sensitized subjects was significantly higher ( $47.1 \pm 17.7$ vs. $43.7 \pm 17.4, p<0.05)$. Occupational dermatitis was present in similar percentages in the two groups and atopic eczema was reported in higher prevalence in those sensitized to fragrance mix-1 vs. non-sensitized $(8.6 \%$ vs. $6.9 \%, p<0.05)$. Dermatitis most frequently involved the face $(20.4 \% ; p<0.05)$ while the other localizations were similar in the two groups. Altogether, $63.9 \%$ of subjects sensitized to fragrance mix- 1 were older than 40 years $(p<0.05)$.

The temporal analysis for fragrance mix-1 sensitization showed a significant increasing trend (Table 2 and Figure 2) from $8.1 \%$ to $9.6 \%$ in males and from $9 \%$ to $13.4 \%$ in females with more than 65 years, in 1996-1998 and 2014-2016, respectively.

Table 2. Sensitization to fragrance mix-1 in different age groups and years evaluated using the logistic regression analysis. Results are reported as Odds Ratios (OR) and Confidence Intervals (95\% CI).

\begin{tabular}{lccccc}
\hline \multicolumn{2}{c}{ Years } & \multicolumn{2}{c}{ Men } & \multicolumn{2}{c}{ Women } \\
\hline \multicolumn{2}{c}{$1996-1998$} & n. $(\%)$ & OR $(95 \%$ CI $)$ & n. $(\%)$ & OR (95\% CI) \\
\hline$<26$ years & $7(3.1)$ & 1 & $29(5.4)$ & 1 \\
\hline \multicolumn{2}{c}{} & $19(6.2)$ & $2.0(0.86-5.0)$ & $37(5.5)$ & $1(0.6-1.7)$ \\
& $26-35$ & $17(7.5)$ & $\mathbf{2 . 5 5 ( 1 . 0 - 6 . 3 )}$ & $45(10)$ & $\mathbf{1 . 9 ( 1 . 2 - 3 . 1 )}$ \\
& $36-45$ & $16(7.7)$ & $\mathbf{2 . 6 6 ( 1 . 1 - 6 . 6 )}$ & $38(10.2)$ & $\mathbf{2 . 0 ( 1 . 2 - 3 . 1 )}$ \\
& $46-55$ & $7(5.3)$ & $1.8(0.6-5.1)$ & $13(4.9)$ & $0.9(0.45-1.7)$ \\
Total & $56-65$ & $10(8.1)$ & $\mathbf{2 . 8 ( 1 . 0 - 7 . 5 )}$ & $25(9.0)$ & $1.7(0.9-3.0)$ \\
\hline
\end{tabular}


Table 2. Cont.

\begin{tabular}{|c|c|c|c|c|c|}
\hline \multicolumn{2}{|c|}{ Years } & \multicolumn{2}{|c|}{ Men } & \multicolumn{2}{|c|}{ Women } \\
\hline \multicolumn{6}{|l|}{ 1999-2001 } \\
\hline$<26$ years & & $14(3.2)$ & 1 & $51(5.4)$ & 1 \\
\hline & $26-35$ & $22(3.7)$ & $1.2(0.8-1.7)$ & $82(6.4)$ & $1.1(0.6-2.3)$ \\
\hline & $36-45$ & $19(4.5)$ & $1.4(0.99-2.1)$ & $71(7.6)$ & $1.4(0.7-2.9)$ \\
\hline & $46-55$ & $25(6.4)$ & $1.8(1.2-2.55)$ & $72(9.2)$ & $2.1(1.0-4)$ \\
\hline & $56-65$ & $28(9.1)$ & $1.9(1.3-2.9)$ & $60(10.0)$ & $3.0(1.6-5.9)$ \\
\hline & $>65$ & $36(10.8)$ & $1.7(1.1-2.5)$ & $61(8.8)$ & $3.7(1.9-6.9)$ \\
\hline Total & & $144(5.8)$ & & 397 (7.6) & \\
\hline \multicolumn{6}{|l|}{ 2002-2004 } \\
\hline$<26$ years & & $6(3.4)$ & 1 & $16(4.2)$ & 1 \\
\hline & $26-35$ & $13(4.7)$ & $1.4(0.52-3.7)$ & $50(8.8)$ & $2.4(1.2-3.9)$ \\
\hline & $36-45$ & $20(8.0)$ & $1.8(0.98-3.3)$ & $35(7.3)$ & $2.2(0.96-6.2)$ \\
\hline & $46-55$ & $13(6.5)$ & $1.9(0.72-5.2)$ & $27(7.2)$ & $1.8(0.94-3.4)$ \\
\hline & $56-65$ & $14(6.8)$ & $2.0(0.77-5.5)$ & $35(9.8)$ & $2.5(1.35-4.6)$ \\
\hline & $>65$ & $10(6.1)$ & $1.8(0.64-5.0)$ & 37 (10.6) & $2.7(1.5-5)$ \\
\hline Total & & $76(6.0)$ & & $200(8.0)$ & \\
\hline \multicolumn{6}{|l|}{$2005-2007$} \\
\hline$<26$ years & & $15(6.0)$ & 1 & $22(4.4)$ & 1 \\
\hline & $26-35$ & $21(7.7)$ & $1.2(0.6-2.1)$ & $23(5.1)$ & $1.3(0.7-2.6)$ \\
\hline & $36-45$ & $15(6.4)$ & $1.3(0.7-2.3)$ & $25(5.6)$ & $1.1(0.5-2.2)$ \\
\hline & $46-55$ & $5(2.8)$ & $0.8(0.6-1.3)$ & $26(7.8)$ & $1.8(1.0-3.2)$ \\
\hline & $56-65$ & $12(7.7)$ & $1.3(0.6-2.3)$ & $31(9.7)$ & $2.3(1.3-4.1)$ \\
\hline & $>65$ & $8(7.7)$ & $1.3(0.5-3.1)$ & $28(12.4)$ & $3.0(1.7-5.4)$ \\
\hline Total & & $76(6.4)$ & & $155(6.8)$ & \\
\hline \multicolumn{6}{|l|}{$2008-2010$} \\
\hline$<26$ years & & $8(4)$ & 1 & $22(5.6)$ & 1 \\
\hline & $26-35$ & $5(2.5)$ & $0.6(0.2-1.9)$ & $26(5.6)$ & $0.98(0.5-1.8)$ \\
\hline & $36-45$ & $7(3.1)$ & $0.8(0.3-2.2)$ & $42(8.4)$ & $1.5(0.9-2.6)$ \\
\hline & $46-55$ & $10(5.8)$ & $1.5(0.9-2.7)$ & $36(8.5)$ & $1.5(0.7-3.8)$ \\
\hline & $56-65$ & $16(11.4)$ & $3.1(1.3-7.3)$ & $33(9.2)$ & $1.7(0.97-3)$ \\
\hline & $>65$ & $9(6.4)$ & $1.4(0.7-2.6)$ & $20(7.6)$ & $1.7(0.6-4.4)$ \\
\hline Total & & $55(5.1)$ & & $179(7.4)$ & \\
\hline \multicolumn{6}{|l|}{ 2011-2013 } \\
\hline$<26$ years & & $6(4.3)$ & 1 & $18(6.3)$ & 1 \\
\hline & $26-35$ & $6(4.3)$ & $0.8(0.4-1.6)$ & $15(5.0)$ & $0.99(0.3-3.1)$ \\
\hline & $36-45$ & $10(6.3)$ & $1.5(0.5-4.2)$ & $27(7.7)$ & $1.2(0.7-2.3)$ \\
\hline & $46-55$ & $20(13.6)$ & $3.5(1.4-8.9)$ & $28(8.3)$ & $1.3(0.7-2.5)$ \\
\hline & $56-65$ & $16(10.1)$ & $2.4(0.9-6.5)$ & 38 (13.7) & $2.3(1.3-4.2)$ \\
\hline & $>65$ & 15 (13.4) & $3.3(1.2-8.9)$ & $38(14.0)$ & $2.4(1.4-4.4)$ \\
\hline Total & & $73(8.5)$ & & $164(9.1)$ & \\
\hline \multicolumn{6}{|l|}{ 2014-2016 } \\
\hline$<26$ years & & $8(6.2)$ & 1 & $18(7.1)$ & 1 \\
\hline & $26-35$ & $5(5.4)$ & $0.9(0.3-2.7)$ & $24(9.2)$ & $1.3(0.7-2.5)$ \\
\hline & $36-45$ & $7(5.9)$ & $0.95(0.3-2.7)$ & $27(8.0)$ & $1.1(0.6-2.1)$ \\
\hline & $46-55$ & $14(9.2)$ & $1.5(0.6-3.8)$ & $21(6.4)$ & $0.9(0.5-1.7)$ \\
\hline & $56-65$ & $10(8.8)$ & $1.6(0.9-3.0)$ & $28(11.1)$ & $1.4(0.5-3.8)$ \\
\hline & $>65$ & $12(9.6)$ & $2.0(1.1-3.6)$ & $36(13.4)$ & $1.6(0.6-4.1)$ \\
\hline Total & & $56(7.7)$ & & $154(9.1)$ & \\
\hline
\end{tabular}




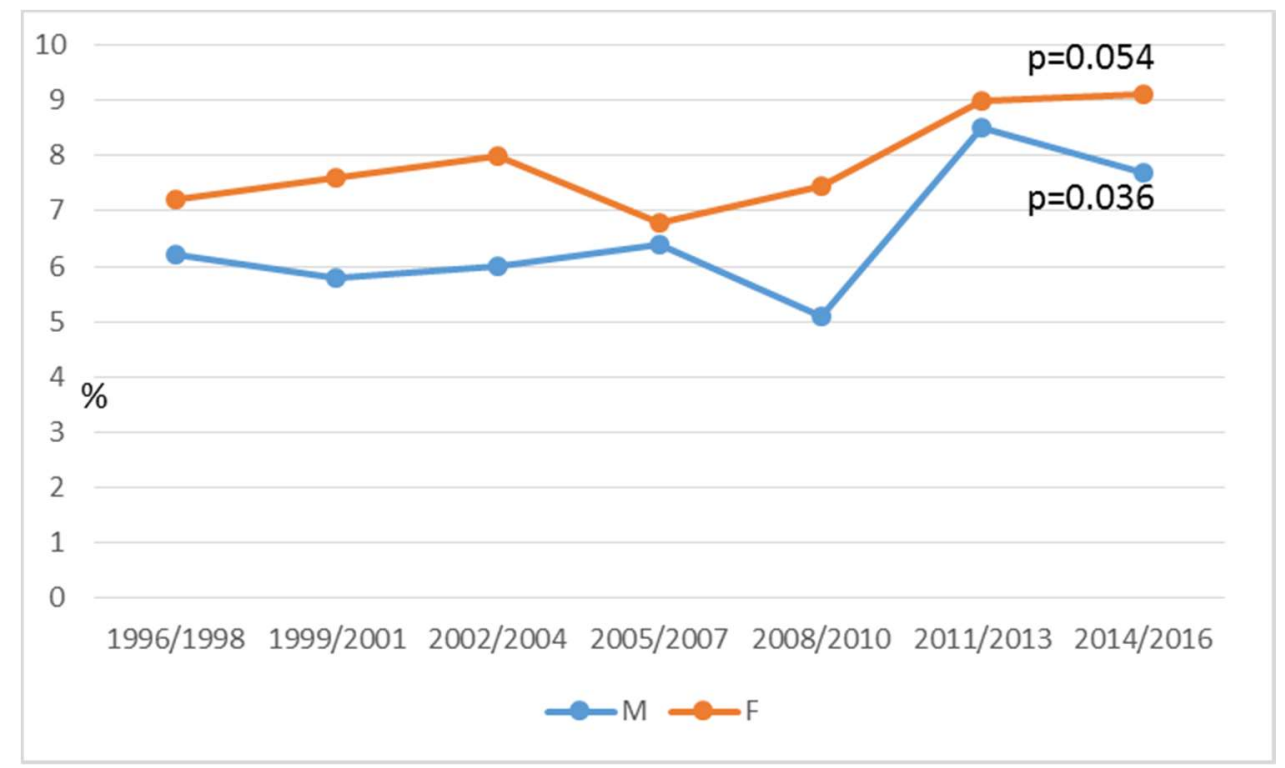

Figure 2. Prevalence of fragrance mix-1 sensitization from 1996 to 2016 in both sexes.

The sensitization to this hapten increased as a function of age with the lower prevalence in younger age classes (3.1\% in men and 5.4\% in women below 26-years-old in 1996-1998 and $6.2 \%$ and $7.1 \%$ in the same group in 2014-2016). Table 2 reports the risk of being sensitized to fragrance mix-1 in different years for age groups and sexes-this analysis shows an increased risk for both sexes to be sensitized in middle ages (36-55 years) in the period 1996-1998, when compared to subjects less than 26-years-old. After 1999, the risk of being sensitized to fragrance mix-1 was significantly higher in older age classes. Crude percentages are increasing during time as well as in relation to age.

Patch test results, in detail, are reported in Figure 3-55.9\% of male and $54.6 \%$ of female patients reacted at $48 \mathrm{~h}(\mathrm{D} 2)$, mainly with " + " reactions (30.7\% in male and $27.8 \%$ in female patients), while the reading at 72 or $96 \mathrm{~h}$ (D3/D4) was $42.9 \%$ in males and $41.7 \%$ in female patients as "++". Women presented with a significantly higher percentage of very strong reactions (" +++ "), in $18.9 \%$ of cases, with respect of $14.9 \%$ of male patients $(p<0.05)$.

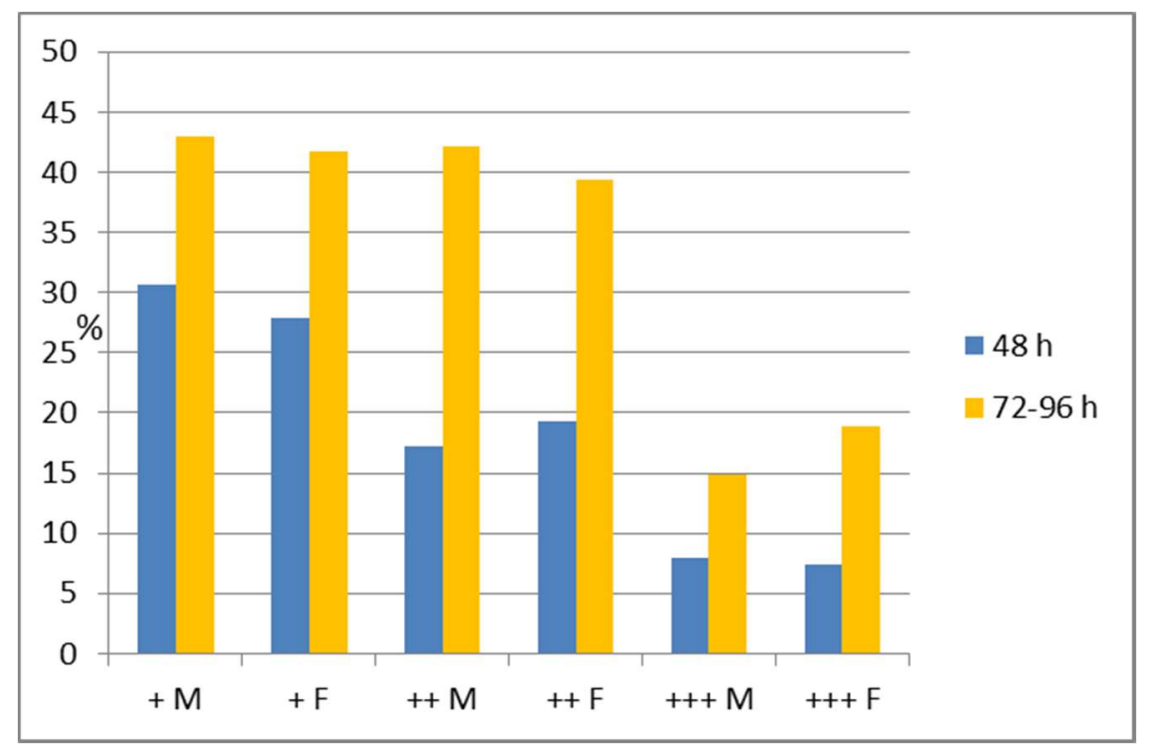

Figure 3. Patch test strength of reactions (\%) to fragrance mix-1 in men (M) and women (F) at 48 and 72-96 h. 


\section{Discussion}

Sensitization to fragrance mix-1 is relevant in our study and it is increasing over time, ranking fourth after metals' sensitization. The important role of fragrance mix-1 sensitization is well known and is in line with other epidemiological studies [3]. The overall prevalence of fragrance mix-1 sensitization was $7.8 \%$, similar to that found in other studies performed in Northern Europe $[9,19]$ and higher than data reported for Spain [2]. The increase of this sensitization over time is in line with previous studies-Bennike in Denmark [9], analyzing data from 1986 to 2015, found that fragrance mix-1 sensitization reached $10.4 \%$ and $7.3 \%$ in women and men, respectively. Nardelli et al. in 2008 in Belgium [8] found a decrease from 1999 to 2005, however the same authors published a fluctuating prevalence of $9.6 \%$ until 2011 [20]. Also, Thyssen et al. in 2008 [7] found a decreasing trend from 1999 to 2007, significant for women. Uter et al. in 2015 [21] reported data on sensitization to fragrance mix from 1999 to 2012 in Germany, Switzerland and Austria finding a prevalence of 8.7\% with a positive trend of sensitization to fragrance mix-1 from 2007 to 2012. In our study, sensitization was increasing in the considered years in both sexes, reaching higher values in the oldest subjects, with a significant time trend effect. We expected a decrease in fragrance mix-1 sensitization from 2008, considering that the International Fragrance Association developed standards for quantitative limits on concentrations of fragrance chemicals in consumer products. They used the quantitative risk assessment (QRA) as a predictive model for establishing safe-use concentrations of fragrance allergens in consumers' products, in order to prevent skin sensitization [22]. However, the sensitization to fragrance mix-1 was increasing in our study as well as in other studies $[9,20,21]$, and the validity of QRA must be questioned. One, and perhaps the most, important gap is that the model did not consider aggregate exposures to fragrance chemicals [23]; that is, what is happening over time. In 2016, the fragrance industry [24] proposed some changes to calculate acceptable exposure levels to fragrance allergens in consumers' products; however, no attention was paid to multiple exposures.

To note, age was positively associated with fragrance mix-1 sensitization with a progressive increase of prevalence, reaching the highest in subjects with more than 65 years; this finding is in line with other results [9] in which sensitization was almost double in people aged $>40$ years in both sexes. Our analysis demonstrated a fluctuation in fragrance mix- 1 sensitization in different years and ages with an increased risk of being sensitized in men and women >36 years in 1996-1998, $>45$ years in 1999-2001, >55 years in 2011-2013 in women, and >65 years in 2014-2016, only for men (OR 2.0; CI 95\% 1.1-3.6). This analysis can suggest that, before 2004, the increase in sensitization to fragrance mix-1 started in middle-aged participants (if compared to subjects younger than 26 years). After 2004, the increase was higher in older people. On the other side, sensitization in young subjects increased significantly over time $(p<0.001)$, confirming the crucial role of this hapten in sensitization also in young people. As exposure to fragrance occurs in our everyday life due to their presence in detergents as well as cosmetics, it is normal that sensitization increases as a function of age. Moreover, the fragrance concentration used in detergents and cosmetics is not protective enough to avoid sensitization in exposed subjects.

Deeply analyzing the characteristics of subjects sensitized to fragrance mix-1, we found an increased risk of having atopic eczema, when compared to non-sensitized patients (8.6\% vs. $6.9 \%$, respectively, $p<0.05)$. This result is in accord with other authors [21,25], and it is probably related to an increase of penetration of this hapten in subjects with an impaired skin barrier. To note, atopic eczema prevalence in our region is lower when compared with other European data [3,9].

Subjects sensitized to fragrance mix-1 had an increased risk of having facial eczema [2,9] due to the presence of this hapten in cosmetics and detergents [26].

Regarding the strength of reaction, women reported a significantly higher prevalence of " +++ " reactions, compared to men-this confirms the more important role of this sensitization in women.

Our study is, in our best knowledge, the largest and longest that reports data on fragrance mix-1 sensitization in Italy. However, it has some limitations: The study population included patients who attended health services for suspected allergic dermatitis, and therefore our results 
may be affected by selection bias; another possible limitation is related to its multicentric design, which may have influenced data recording in different centers, although all participants agreed to use a standardized protocol.

\section{Conclusions}

Our study found a high sensitization to fragrance mix-1 Italy with an increase in age and calendar years. Our results, in line with other European data, confirm the need to reduce the fragrance mix-1 content in cosmetics and detergents to stop this sensitization. Many data in the literature reported the positive effect obtained in limitation of some allergens in common products, such as nickel content in metal objects [26-28], chromium in concrete [16,29], and euxylK400 as preservatives [30]. For that reason, it is time to do something more to prevent sensitization to fragrance mix- 1 .

Author Contributions: F.L.F. designed the study, did the statistical analysis and wrote the paper. M.M. did tables and figures and participated to the discussion of results.

Funding: This research received no external funding.

Acknowledgments: We acknowledge all member centres of the North-East Italy Contact Dermatitis Group (NEICDG): Clinica Dermatologica dell'Università di Padova, Divisione Dermatologica Ospedale Santa Maria degli Angeli di Pordenone, Unità di Dermatologia, Ospedale Santa Chiara di Trento, Italy; Unità di Dermatologia, Ospedale di Rovigo, Italy; Unità di Dermatologia, Ospedale San Martino, Belluno, Italy; Unità di Dermatologia, Azienda sanitaria dell'Alto Adige, Bolzano Italy.

Conflicts of Interest: The authors declare no conflict of interest.

\section{References}

1. Frosch, P.J.; Johansen, J.D.; Schuttelaar, M.L.A. Patch test results with fragrance markers of the baseline series-Analysis of the European surveillance system on contact allergies (ESSCA) network 2009-2012. Contact Dermat. 2015, 73, 163-171. [CrossRef]

2. Silvestre, J.F.; Mercader, P.; González-Pérez, R. Sensitization to fragrances in Spain: A 5-year multicentre study (2011-2015). Contact Dermat. 2018. [CrossRef]

3. Uter, W.; Aberer, W.; Armario-Hita, J.C. Current patch test results with the European baseline series and extensions to it from the 'European Surveillance System on Contact Allergy' network, 2007-2008. Contact Dermat. 2012, 67, 9-19. [CrossRef]

4. Uter, W.; Johansen, J.D.; Börje, A.; Karlberg, A.T.; Lidén, C.; Rastogi, S.; Roberts, D.; White, I.R. Categorization of fragrance contact allergens for prioritization of preventive measures: Clinical and experimental data and consideration of structure-activity relationships. Contact Dermat. 2013, 69, 196-230. [CrossRef] [PubMed]

5. Hafner, M.F.S.; Munhoz, S.D.G.; Jeldes, A.G.; Lazzarini, R. Positive results of patch tests with fragrance markers: Analysis of a 15-year period at a Brazilian dermatology center. An. Bras. Dermatol. 2018, 93, 910-912. [CrossRef] [PubMed]

6. Diepgen, T.L.; Ofenloch, R.; Bruze, M.; Cazzaniga, S.; Coenraads, P.J.; Elsner, P.; Goncalo, M.; Svensson, Å.; Naldi, L. Prevalence of fragrance contact allergy in the general population of five European countries: A cross-sectional study. Br. J. Dermatol. 2015, 173, 1411-1419. [CrossRef]

7. Thyssen, J.P.; Carlsen, B.C.; Menne, T.; Johansen, J.D. Trends of contact allergy to fragrance mix I and Myroxylon pereirae among Danish eczema patients tested between 1985 and 2007. Contact Dermat. 2008, 59, 238-244. [CrossRef] [PubMed]

8. Nardelli, A.; Carbonez, A.; Drieghe, J.; Goossens, A. Results of patch testing with fragrance mix 1, fragrance mix 2, and their ingredients, and Myroxylon pereirae and colophonium, over a 21-year period. Contact Dermat. 2013, 68, 307-313. [CrossRef] [PubMed]

9. Bennike, N.H.; Zachariae, C.; Johansen, J.D. Trends in contact allergy to fragrance mix I in consecutive Danish patients with eczema from 1986 to 2015: A cross-sectional study. Br. J. Dermatol. 2016, 176, 1035-1041. [CrossRef] [PubMed]

10. Uter, W. Contact allergy to fragrances: Current clinical and regulatory trends. Allergol. Sel. 2017, 4, 190-199. [CrossRef] [PubMed] 
11. de Groot, A.C.; Frosch, P.J. Adverse reactions to fragrances. A clinical review. Contact Dermat. 1997, 36, 57-86. [CrossRef]

12. Johansen, J.D.; Lepoittevin, J.-P. Fragrances. In Contact Dermatitis, 5th ed.; Johansen, J., Frosch, P., Lepoittevin, J.-P., Eds.; Springer: Heidelberg, Germany; Dordrecht, The Netherlands; London, UK; New York, NY, USA, 2011; pp. 607-627.

13. Directive 2003/15/EC of the European Parliament and of the Council Directive of February 27, 2003 amending Council. Directive of July 27, 1976 on the approximation of the laws of the Members States relating to cosmetic products (76/768/EEC). Off. J. Eur. Union 2003, L66, 26-35.

14. Scientific Committee on Consumer Safety SCCS OPINION on Fragrance Allergens in Cosmetic Products. Available online: http:/ / ec.europa.eu/health/scientific_committees/consumer_safety/docs/sccs_O_102.pdf (accessed on 29 January 2019).

15. Inception Impact Assessment on Fragrance Allergens Labelling. Available online: https://ec.europa.eu/ growth/content/inception-impact-assessment-fragrance-allergens-labelling-published_en (accessed on 29 January 2019).

16. Rui, F.; Bovenzi, M.; Prodi, A. Nickel, cobalt and chromate sensitization and occupation. Contact Dermat. 2010, 62, 225-231. [CrossRef]

17. Johansen, J.D.; Aalto-Korte, K.; Agner, T.; Andersen, K.E.; Bircher, A.; Bruze, M.; Cannavó, A.; Giménez-Arnau, A.; Gonçalo, M.; Goossens, A.; et al. European Society of Contact Dermatitis guideline for diagnostic patch testing — Recommendations on best practice. Contact Dermat. 2015, 73, 195-221. [CrossRef]

18. Wilkinson, D.; Fregert, S.; Magnusson, B. Terminology of contact dermatitis. Acta Derm. Venereol. 1970, 50, 287-292.

19. Mowitz, M.; Svedman, C.; Zimerson, E.; Isaksson, M.; Pontén, A.; Bruze, M. Simultaneous patch testing with fragrance mix I, fragrance mix II and their ingredients in southern Sweden between 2009 and 2015. Contact Dermat. 2017, 77, 280-287. [CrossRef]

20. Nardelli, A.; Carbonez, A.; Ottoy, W. Frequency of and trends in fragrance allergy over a 15-year period. Contact Dermat. 2008, 58, 134-141. [CrossRef]

21. Uter, W.; Fiebler, C.; Gefeller, O. Contact sensitization to fragrance mix I and II, to Myroxylon pereirae resin and oil of turpentine: Multifactorial analysis of risk factors based on data of the IVDK network. Flavour Fragr. J. 2015, 30, 255-263. [CrossRef]

22. Api, A.M.; Basketter, D.A.; Cadby, P.A. Dermal sensitization quantitative risk assessment (QRA) for fragrance ingredients. Regul. Toxicol. Pharmacol. 2008, 52, 3-23. [CrossRef] [PubMed]

23. Comiskey, D.; Api, A.M.; Barratt, C. Novel database for exposure to fragrance ingredients in cosmetics and personal care products. Regul. Toxicol. Pharmacol. 2015, 72, 660-672. [CrossRef] [PubMed]

24. Basketter, D.; Safford, B. Skin sensitization quantitative risk assessment: A review of underlying assumptions. Regul. Toxicol. Pharmacol. 2016, 74, 105-116. [CrossRef]

25. Thyssen, J.P.; Linneberg, A.; Engkilde, K. Contact sensitization to common haptens is associated with atopic dermatitis: New insight. Br. J. Dermatol. 2012, 166, 1255-1261. [CrossRef] [PubMed]

26. Heisterberg, M.V.; Menne, T.; Johansen, J.D. Contact allergy to the 26 specific fragrance ingredients to be declared on cosmetic products in accordance with the EU cosmetics directive. Contact Dermat. 2011, 65, 266-275. [CrossRef] [PubMed]

27. Garg, S.; Thyssen, J.P.; Uter, W. Nickel allergy following European Union regulation in Denmark, Germany, Italy and the U.K. Br. J. Dermatol. 2013, 169, 854-858. [CrossRef] [PubMed]

28. Thyssen, J.P. Nickel and cobalt allergy before and after nickel regulation-evaluation of a public health intervention. Contact Dermat. 2011, 65, 1-68. [CrossRef] [PubMed]

29. Teixeira, V.; Coutinho, I.; Gonçalo, M. Allergic Contact dermatitis to metals over a 20-year period in the Centre of Portugal: Evaluation of the effects of the European directives. Acta Med. Port. 2014, 27, 295-303. [CrossRef] [PubMed]

30. Filon, F.L.; Bongiorni, L.; Prodi, A. Effectiveness of European Regulation on Euxyl K400 Sensitization in Northeastern Italy from 1996 to 2012 and Occupation. Dermatitis 2017, 28, 327-328. [CrossRef] [PubMed]

(C) 2019 by the authors. Licensee MDPI, Basel, Switzerland. This article is an open access article distributed under the terms and conditions of the Creative Commons Attribution (CC BY) license (http:/ / creativecommons.org/licenses/by/4.0/). 